\title{
LUDIC APPROACH OF THE SCIENTIFIC METHOD IN BIOCHEMICAL EDUCATION
}

Maia, W.B. ${ }^{1}$, Martins, J.M. ${ }^{1}$, Furtado, V.C. ${ }^{1}{ }^{2}$, Aquino, I.J. ${ }^{1}$, Silva, L.G.C. ${ }^{1}$, Barreto, S.B. ${ }^{1}$, Monteiro, J.M. ${ }^{1}$, Lima, V.L.M. ${ }^{1}$, de Meis, L. ${ }^{3}$, Rangel, D. ${ }^{3}$, Oliveira, M.I.P. ${ }^{1}$, Cordeiro, M.F.

${ }^{1} \mathrm{UFPE} ;{ }^{2} \mathrm{UPE} ;{ }^{3} \mathrm{UFRJ}$

Education in the current times concerns to the intellectual autonomy, the capacity of decision and the possibilities of the student in making the difference. This work arose due to multi-transdisciplinary perception of an educator's team from UFPE and UFRJ, to whom scientific research means intentional intellectual activity to attend human needs. As an answer to teacher's questions about student difficulties of learning scientific methodology, it was included a ludic activity into classroom of high school, graduation and postgraduate levels. First of all a CDROM entitled: "O Método Científico: Uma Leitura Virtual" was made with adobe flash program and it was used as neurodidactic strategy (auditory and visual stimulus). After thirty minutes of ludic activities, discussions about importance and utility of scientific method took place, and the Science and the Technology as subjects matters arose. So, a democratic and interfacial environment was produced. As a result of using this didactic activity it was stimulated curiosity, awakened up attention, developed specific abilities of observation, eased association of ideas and improved capacity of analysis and synthesis in all the groups. Ludic activities in education create possibilities of sociability (such as consolidation of student's individuality), and also stimulate the interest in the Sciences. In this way, for the development of educational projects focused on paradigms changes that lead to the rise of a new didactic culture, the use of diverse interfacial resources becomes necessary.

Keywords: Ludic activity, neurodidactic strategy, biochemical education. 